\title{
Self-digital e a (re)produção de imagens organizacionais nas
}

\section{mídias sociais ${ }^{1}$}

\section{SELF-DIGITAL AND THE (RE)PRODUCTION OF ORGANIZATIONAL IMAGES IN SOCIAL

\section{Tatiane Rodrigues Carvalho de Oliveira ${ }^{i}$}

ORCID: https://orcid.org/0000-0002-5184-4874

(Universidade do Minho, Doutorado em Ciências da Comunicação. Braga, Portugal.)

\section{Victor Laus-Gomes ${ }^{i i}$}

ORCID: https://orcid.org/0000-0002-8497-4392

(Universidade Católica de Brasília, Programa de Pós-Graduação em Educação, Mestrado Profissional Inovação em Comunicação e Economia Criativa. Brasília, DF, Brasil)

Recebido em 18/11/2019. Aprovado em 23/12/2020.

\section{RESUMO}

A proliferação do uso das imagens é uma realidade da comunicação digital. Com base nos pressupostos da teoria da complexidade, observa-se que a interação com as imagens das empresas, ao longo do tempo, constrói um processo identificatório e relacional com os usuários no ambiente digital. As imagens (re)produzem narrativas essenciais para a construção de identidades e do selfdigital das organizações. Neste artigo são analisadas imagens do Instagram do banco público brasileiro Caixa Econômica Federal.

Palavras-chave: Imagens organizacionais. Identidade organizacional. Mídias sociais.

\section{ABSTRACT}

The proliferation of the use of images is a reality of digital communication. Based on the assumptions of complexity theory, it is observed that the interaction with business images, over time, builds a process of identification and relational with users in the digital environment. Images (re)produce essencial narratives for the construction of identities and the self-digital of organizations. This article analyzes Instagram images from the Brazilian public bank Caixa Economica Federal.

Keywords: Organizational images. Organizational identity. Social media.

\footnotetext{
${ }^{1}$ Trabalho desenvolvido com apoio do Conselho Nacional de Desenvolvimento Científico e Tecnológico (CNPq) - Chamada Universal MCTI/CNPq No 01/2016.
} 


\section{Introdução}

A apreciação de imagens pela sociedade é antiga. Desde as pinturas rupestres nas cavernas até o surgimento das primeiras artes plásticas, a reprodução do olhar precisa ganhar vida. É como se precisássemos transportar a realidade para uma imagem para que ela ficasse ali disponível, como um espaço de recordação, de memória. Segundo Flusser (2011), as imagens são superfícies que pretendem representar algo e funcionam como mediações entre o homem e o mundo.

As mudanças trazidas com as novas tecnologias, especialmente com as mídias sociais ${ }^{2}$, passam pela proliferação do uso das imagens. Para Han (2016), as imagens não se colocam apenas como cópias, mas também como modelos. Diante da dispersão, da sensação de desterritorialização e fluidez das relações do ambiente virtual, os sintomas de falta de filiação social parecem ser características comuns nesses tempos de profundas transformações. Isso nos leva a uma relação entre o processo de construção de identidades e a utilização autorreferencial de imagens, dentro de padrões estéticos técnicos e simbólicos.

Para as organizações, as imagens representam a projeção da identidade, traçam comportamentos, propõem experiências e estilos, reforçam a presença de produtos e serviços. Assim como os indivíduos, as empresas recorrem a artifícios que possam representar uma imagem desejável para a sociedade em que estão inseridas. Nosso estudo tem o objetivo de explorar e responder a pergunta: como as empresas constroem e representam suas identidades nos ambientes digitais por meio de imagens? E, ainda, propor um método para análise de imagens postadas por organizações nas mídias sociais, com base no conceito de self-digital ${ }^{3}$. Para ilustrarmos nossa proposta, analisamos as imagens da Caixa Econômica Federal, no perfil @caixa, na plataforma Instagram.

Nossa reflexão segue os pressupostos da teoria da complexidade de Edgar Morin $(2000)^{4}$. Partimos da hipótese de que as interações nas mídias sociais, por meio de

\footnotetext{
${ }^{2}$ De acordo com Recuero (2010), redes e mídias sociais são diferentes. Para ela, as redes são metáforas para grupos sociais. Já a mídia social é um conjunto de dinâmicas de criação de conteúdo, difusão de informações e trocas dentro dos grupos sociais estabelecidos da rede social. Segundo a autora, é mídia social porque permite a apropriação para a sociabilidade, a partir da construção do espaço social e da interação com outros atores. Trabalharemos com o conceito de Recuero para mídia social neste estudo. Disponível emhttp://www.raquelrecuero.com/arquivos/midia x rede social.html e http://www.raquelrecuero.com/arquivos/o_que_e_midia_social.html. Acesso realizado em 22 de agosto de 2019.

${ }^{3} \mathrm{O}$ conceito de self-digital é desenvolvido por Oliveira (2019), representa uma reflexividade do self no ambiente digital, e será pormenorizado ao longo deste artigo.

${ }^{4} \mathrm{O}$ novo milênio trouxe à contemporaneidade o confronto dos paradigmas sociais da simplicidade e da
} 
imagens, contribuem para a construção do processo identificatório das organizações. Como não há contato pessoal, a virtualização reforça a interação com o outro por meio de uma identidade virtual. As imagens (re)presentam essa construção identitária e possibilitam um processo relacional da empresa no ambiente digital.

\section{Identidade das organizações e o percurso metodológico}

Uma premissa básica a todo pesquisador é a observação. De acordo com Morin (2012), é necessário reintegrar e conceber os sistemas humanos aos sistemas observados. É preciso recorrer à autoanálise e à autorreflexão para tentar considerar criticamente nosso lugar, nosso estatuto e, assim, contornar a relação sujeito/objeto na produção do conhecimento.

Para compor nossa construção metodológica, partimos do paradigma da complexidade, buscando realizar a integração reflexiva de saberes e a inevitável comunicação entre observador e seu objeto, de maneira a conceber a unidade e a diversidade humanas; conceber os aspectos atualmente separados e compartimentalizados, que são físicos, biológicos, psicológicos, sociais, mitológicos, econômicos, históricos; juntar concepções de verdades separadas que se excluem; e aliar dimensões científicas, epistemológicas e reflexivas (filosóficas).

Conceituar a identidade organizacional é uma tarefa complexa, multimensional. A construção da identidade das organizações pode ser considerada resultado da ação de sujeitos, de indivíduos, que constituem, em um determinado contexto, o processo de formação da imagem da empresa na sociedade. A identidade de uma organização está relacionada à pergunta "quem somos nós na organização?". Apesar de acharmos que as identidades nas organizações são algo completo e coerente, organizado e estável, sob a perspectiva da complexidade, elas guardam em si o desordenado, o desorganizado e instável.

Para autores como Etkin e Schvarztein (2011), a identidade de uma organização se define por tudo aquilo que permita distingui-la como singular e diferente das demais. Ela se materializa através de uma estrutura, ou seja, pelos recursos que dispõe e pelo uso que dá a eles, pelas suas relações com seus integrantes e entorno, isto é, os sujeitos que

complexidade. Segundo Morin, o paradigma da simplicidade é de ordem, já o da complexidade é de relação dialógica entre ordem, desordem e organização. Somente o pensamento complexo é capaz de reunir, contextualizar, globalizar e ao mesmo tempo capaz de conhecer o singular, o individual (MORIN, 2000, p. 30-31). 
compõe interna e externamente a organização, pelos seus propósitos e programas existentes para sua implementação e controle. Assim, Etkin e Schvarztein (2011) esclarecem que identidade e estrutura são conceitos complementares e não podem ser compreendidos um sem o outro, em que as organizações se definem pela presença de relações internas e externas complementares, concorrentes e antagônicas. Os autores também afirmam que as organizações se definem pela presença de permanência e transitoriedade, coesão e dispersão, certeza e incerteza, estabilidade e instabilidade, autonomia e dependência.

De acordo com Morin (1980), a ideia de autorreferência da organização é uma ideia-chave da identidade. No entanto, não é uma ideia fechada. Como a organização é autorreferente, ela também é auto-exorreferente. Isso é, a organização, considerando o princípio da complexidade, tem de confrontar permanentemente o seu princípio egocêntrico, voltada para si, mas também o princípio da realidade, nesse caso os concorrentes, fornecedores, atores e contextos externos à organização. Esses universos, apesar de serem distantes e até mesmo opostos, são também indissociáveis e interdependentes. Dessa forma, a organização é simultaneamente egocêntrica e realista. Necessita dessa objetividade exatamente para evitar erros de computação, decisão e de ação. Baldissera (2007) entende que as organizações, como um sistema auto-eco-organizado, fecham-se estrategicamente para construírem-se e instituírem-se com uma dada coerência/ordenação frente ao outro. No entanto, abrem-se para, em tensões e disputas com suas alteridades, atualizarem-se e tornarem mais complexas as relações dialógico-recursivas.

Assim, os processos identificatórios estão presentes nos constantes movimentos de abertura/fechamento, simpatia/antipatia, aproximação/afastamento, aceitação/rejeição, entre outros. Baldissera (2007) reforça que a forma assumida pela identidade organizacional é simbólica, provisória e processual e é permanentemente atualizada nas complexas negociações realizadas nas fronteiras culturais. $\mathrm{O}$ autor também propõe que as identidades organizacionais são da qualidade do híbrido, pressupõem processos e relações dialógicas, dialéticas, recursivas e hologramáticas que articulam, de diferentes formas, as inter-relações, cruzamentos, colagens, misturas, interações, expropriações de sujeitos. Cada uma dessas identidades individuais e paradigmas compreende uma multiplicidade de possibilidades identificatórias que, tensionadas no permanente processo de construção da identidade organizacional, resultam em algo diferente das identidades individuais (e mais complexo), mas com a sobrevivência delas.

As mudanças com as novas tecnologias possibilitaram aos sujeitos que participam da organização, de alguma maneira, que tenham um espaço digital para construção de sua imagem para o outro, de forma a tornar esse fluxo dispersivo mais complexo ainda. No 
ambiente virtual, as trocas e tensões de discursos da organização tendem a se dar no âmbito do imaginário. Dessa forma, todos os empregados da empresa, fornecedores, parceiros, podem ser considerados passíveis de assumir o discurso da organização no ambiente digital, tornando o papel da Comunicação Organizacional essencial para integração de vozes e narrativas das empresas. A Comunicação Organizacional torna-se, portanto, a reflexividade da identidade da organização, um fio condutor de alinhamento dos discursos, de significações, que são tensionados pelos sujeitos da organização. Instaura-se um universo simbólico, um conjunto de significados atribuídos à realidade interpretada por cada sujeito. Sem a comunicação como instrumento para essa reflexividade da identidade, como o fio, a formação do discurso da organização tenderia a ser difusa, sem coerência narrativa, desorganizada. Essa compreensão também dá conta que a Comunicação Organizacional não respeita espaços delimitados e planejados. Também ocorre de maneira incerta, desordenada e, sendo assim, não se reduz à fala autorizada da organização.

Por meio do fio condutor da Comunicação Organizacional podemos observar em perfis nas mídias sociais como o Instagram, que a identidade é refletida a partir de projetos, expectativas, estilos, bens de consumo, cultura, com uma infinidade de narrativas de caráter simbólico que dão pistas da representação reflexiva das organizações. Podemos encarar essa imagem virtual que transmite a ideia de reflexividade sob dois aspectos: uma como modelo ideal e a outra como um duplo de si mesmo. De acordo com Morin (1980), esse modelo ideal não está formado, moldado, figurado. Ele é virtual e está em permanente atualização. Segundo o autor, ele se atualiza a cada momento de existência. Em cada nova situação de ordem ou desordem, esse modelo ideal conduz e comanda a formação do ser. Já o duplo é um alter ego à nossa semelhança que se apresenta como um espectro corporal. O duplo, para Morin (1980), seria então uma representação interior ao espírito, impondo-se como evidência em nosso reflexo na água, na sombra projetada pelo nosso corpo, de forma a ser projetado para fora de si, sob a forma de alter ego. Segundo o autor, o duplo comporta efetivamente a vontade mais ardente do sujeito egocêntrico: nunca deixar de ser o centro do mundo, nunca deixar de ser sujeito, nunca morrer.

Oliveira (2019) define como self-digital o processo de formação identitária nas mídias sociais. A reflexividade é o resultado de uma oscilação entre o modelo de um ideal que acompanha permanentemente a organização, que a faz atualizar-se constantemente, e um verdadeiro duplo concreto, completo e egocêntrico, que se manifesta sob a forma de um alter ego. O self-digital é, portanto, uma espécie de personagem nas mídias sociais, que se reafirma constantemente na reflexividade do duplo, uma oscilação simultânea entre o real e o virtual. No virtual, com a imagem servindo como um modelo ideal do ser, da 
existência, do que se pretende projetar, que se reafirma de forma simbólica no imaginário, gerando legitimação e reverência. Ao mesmo tempo real, pela projeção do alter ego completo, projetado para fora de si pelas imagens, pelas interações, que fortalecem e facilitam seus níveis de contato, seus vínculos e associações. Ao longo do tempo, estabelece-se um processo relacional das organizações com seus públicos no universo digital.

Han (2016) sentencia que estamos diante de um momento de transição crítico, a revolução digital. Para o autor, o homem digital é alguém penetrante, que mantém um perfil, se expõe, solicita atenção e assim dissolve sua identidade privada. As mídias sociais são meios que trabalham com a lógica do imperativo da transparência, fazendo com que muitas vezes antecipem-se informações que ainda não estão maduras ou que não foram suficientemente apuradas, em nome da exigência de participação naquele ambiente. De acordo com Han (2016), a comodidade da comunicação pelo digital faz evitarmos cada vez mais contato direto com as pessoas reais, faz com que o encontro real desapareça. $\mathrm{O}$ digital submete uma reconstrução radical entre o real, o imaginário e o simbólico. Segundo o autor, o smartphone faz as vezes de um espelho digital e abre uma brecha narcísica do imaginário. Para McLuhan (1964), o mito do Narciso, que tomou seu próprio reflexo na água, mostra que os homens logo se tornam fascinados por qualquer extensão de si mesmo em qualquer material que não seja ele próprio.

Nesse contexto, outro importante fator para considerarmos é o imperativo da felicidade. De acordo com Freire Filho (2010), na era da reprodutibilidade científica, a felicidade desponta como um recurso estratégico para otimização da saúde, bemestar e da produtividade. É a lógica de que ao sermos felizes, isso nos ajuda a ser mais bem-sucedidos. Nas mídias sociais, esse imperativo ganha seus contornos por meio da apresentação das imagens. Os perfis são individuais e cada um tem a liberdade de escolher suas imagens. No entanto, as imagens selecionadas ganham representações de padrões já estabelecidos na sociedade para legitimação social.

Dessa maneira, segundo Han (2016), as imagens não são apenas cópias, mas também modelos. Para ele, procuramos refúgio nas imagens, nesses modelos, para nos tornarmos melhores, mais belos, mais vivos. $\mathrm{O}$ meio digital consuma uma "inversão icônica" que faz com que as imagens pareçam mais vivas, melhores que a realidade, percebida como deficiente. Assim, destroem o valor icônico original da imagem, tornamse referência do real. A produção excessiva de imagens pode ser interpretada como uma reação de defesa e fuga.

Em nossa pesquisa, identificamos um conjunto de elementos que permeia as imagens reproduzidas nas mídias sociais e é caracterizado a seguir. 
Presença: esse elemento é crucial para a relação de elo da imagem com o usuário. Sem a presença "virtual” não há como interagir e gerar vínculos.

Narcisismo: como há uma ambição individual de captura de relações sociais no meio digital, há uma projeção para que a mídia social seja um perfeito espelho dele mesmo, só que com a diferença da perfeição técnica das imagens.

Felicidade: é um atributo que oferece uma certa autoconfiança, uma autoridade dentro do ambiente, o legitima, vez que aos seguidores só cabe a aprovação da reprodução desse modelo sociológico.

Hiper-realidade: as imagens funcionam como modelos de referência, com a magia e a idolatria da perfeição técnica do que ali está representado, como se fossem melhores, mais belas do que o real.

Cultura: decifrar imagens fotográficas implicaria, entre outras coisas, também o deciframento de condições culturais. Isso porque o que leva às escolhas culturais não transparece na imagem fotográfica.

Tendo em vista o objetivo deste trabalho, selecionamos o Instagram como a mídia social em que vamos estudar as imagens organizacionais da Caixa Econômica Federal. O Instagram é uma mídia social para compartilhamento de imagens com grande penetração entre os usuários. No dia 20 de junho de 2018, a empresa anunciou que atingiu a marca de 1 bilhão de usuários ativos em todo o mundo ${ }^{5}$. Esse número representou um crescimento de 300\% em relação a 2014, quando possuía 200 milhões de usuários.

Além do crescimento de usuários pessoas físicas, o Instagram também atraiu as organizações empresariais. De acordo com estatísticas do site Instagram (2019), cerca de $70 \%$ dos negócios nos Estados Unidos incluíram o Instagram na estratégia. No mundo todo, são mais de 25 milhões de perfis comerciais, dois milhões de anunciantes, mais de 200 milhões de usuários ${ }^{6}$ que acessam um perfil comercial por dia. Segundo o site Instagram (2019), 1/3 das histórias mais visualizadas são de empresas ${ }^{7}$. Segundo o relatório Global Digital Report ${ }^{8}$, a audiência para anúncios do Instagram é de 895 milhões de usuários, sendo composta de 50\% mulheres e 50\% de homens, com idades principalmente

5 CANALTECH. Instagram bate marca de 1 bilhão de usuários ativos. Disponível em https://canaltech.com.br/redes-sociais/instagram-bate-marca-de-1-bilhao-de-usuarios-ativos-116344/ Acesso em 22 de agosto de 2019.

${ }^{6}$ INSTAGRAM EMPRESAS. Disponível em https://business.instagram.com/getting-started/ Acesso em 18 de dezembro de 2019.

${ }^{7}$ INSTAGRAM EMPRESAS. Disponível em https://business.instagram.com/getting-started/ Acesso em 18 de dezembro de 2019.

${ }^{8}$ GLOBAL DIGITAL REPORT. Disponível em https://wearesocial.com/global-digital-report-2019. Acesso em 18 de dezembro de 2019 (pp.84-114). 
entre 18 a 34 anos. O Instagram ocupa o segundo lugar em número de audiência para anúncios, apenas atrás do Facebook. Muitas organizações decidiram investir na mídia de compartilhamento de fotos e vídeos em virtude do lançamento do Instagram Empresas, que possui informações de contato, dados para análise de desempenho e possibilidade de criar anúncios.

Cabe-nos ressaltar o caráter limitado dessa relação social no ambiente virtual. A interação do perfil da empresa com o outro ocorre somente a partir da visualização da imagem pelo usuário, o que nem sempre acontece. No caso do Instagram, a interação ocorre a partir da troca de imagens, textos da legenda, comentários na imagem, curtidas, mensagens personalizadas no perfil privado. $\mathrm{O}$ caráter simbólico da imagem ganha força exatamente porque é no campo simbólico que é possível atingir o elo de proximidade e assim permitir a geração de um vínculo e identificação junto ao usuário.

\section{A Caixa e o perfil no Instagram}

A Caixa Econômica Federal (CAIXA, 2019) se apresenta em seu site oficial com a missão de "promover o desenvolvimento sustentável do Brasil, gerando valor aos clientes e à sociedade como instituição financeira pública e agente de políticas públicas de Estado". Na sua história, o banco conta que foi criado em 1861 pelo imperador Dom Pedro II. A instituição afirma, ainda, que é $100 \%$ pública e que exerce um papel fundamental no desenvolvimento urbano e social do país, em setores como habitação, saneamento básico, infraestrutura, poupança e prestação de serviços. Além disso, apoia inúmeras atividades artístico-culturais, educacionais e desportivas, garantindo um lugar de destaque no dia a dia das pessoas. Desde 2004, o banco afirma patrocinar o esporte paralímpico e possuir mais de 4.000 funcionários treinados em libras.

Em 12 de janeiro de 2019, o banco completou 158 anos. De acordo com dados da empresa, a Caixa atende cerca de 101,1 milhões de clientes, dos quais 98,2 milhões são pessoas físicas e 2,8 milhões são pessoas jurídicas. A rede Caixa possui 54,2 mil postos de atendimento. São 4,1 mil agências e postos de atendimento, 21,2 mil correspondentes bancários e lotéricos e 28,8 mil terminais de autoatendimento. Atualmente, a empresa conta com 84,4 mil empregados ${ }^{9}$.

Neste estudo, analisamos o perfil do Instagram @CAIXA. O perfil é oficial e pos-

${ }^{9}$ Dados obtidos junto à Caixa Econômica Federal em 09 de setembro de 2019. 
suía 166 mil seguidores em consulta realizada no dia 03 de setembro de 2019. O artigo considera as imagens postadas entre os dias 11 de julho e 01 de setembro de 2019.

Figura 1 - Perfil CAIXA
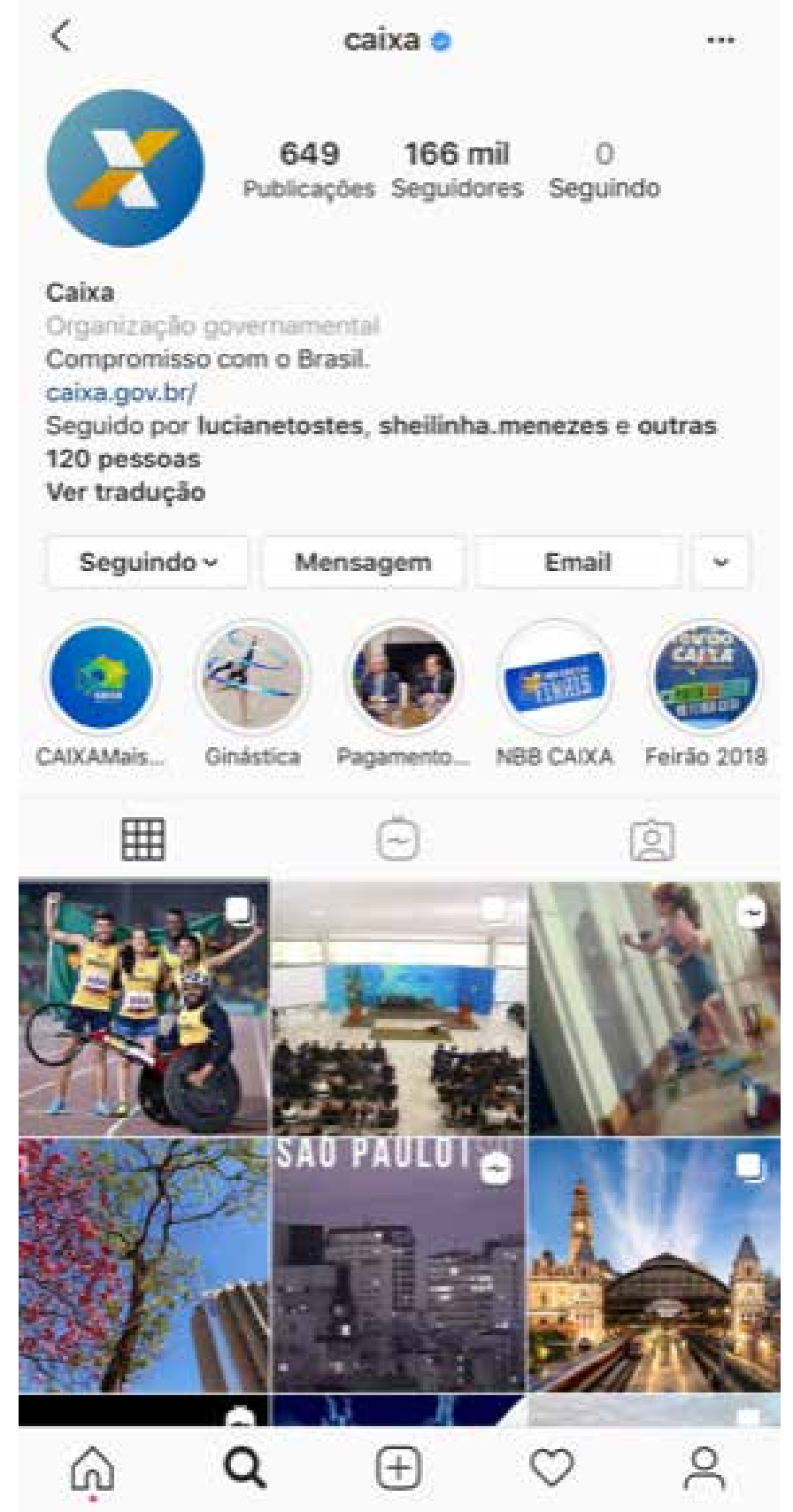

Fonte: Aplicativo Instagram. Imagem obtida em consulta ao perfil CAIXA. Acesso em 03 de setembro de 2019. 
Figura 2 - Imagens das postagens realizadas entre os dias 11 de julho até 01 de setembro de 2019.

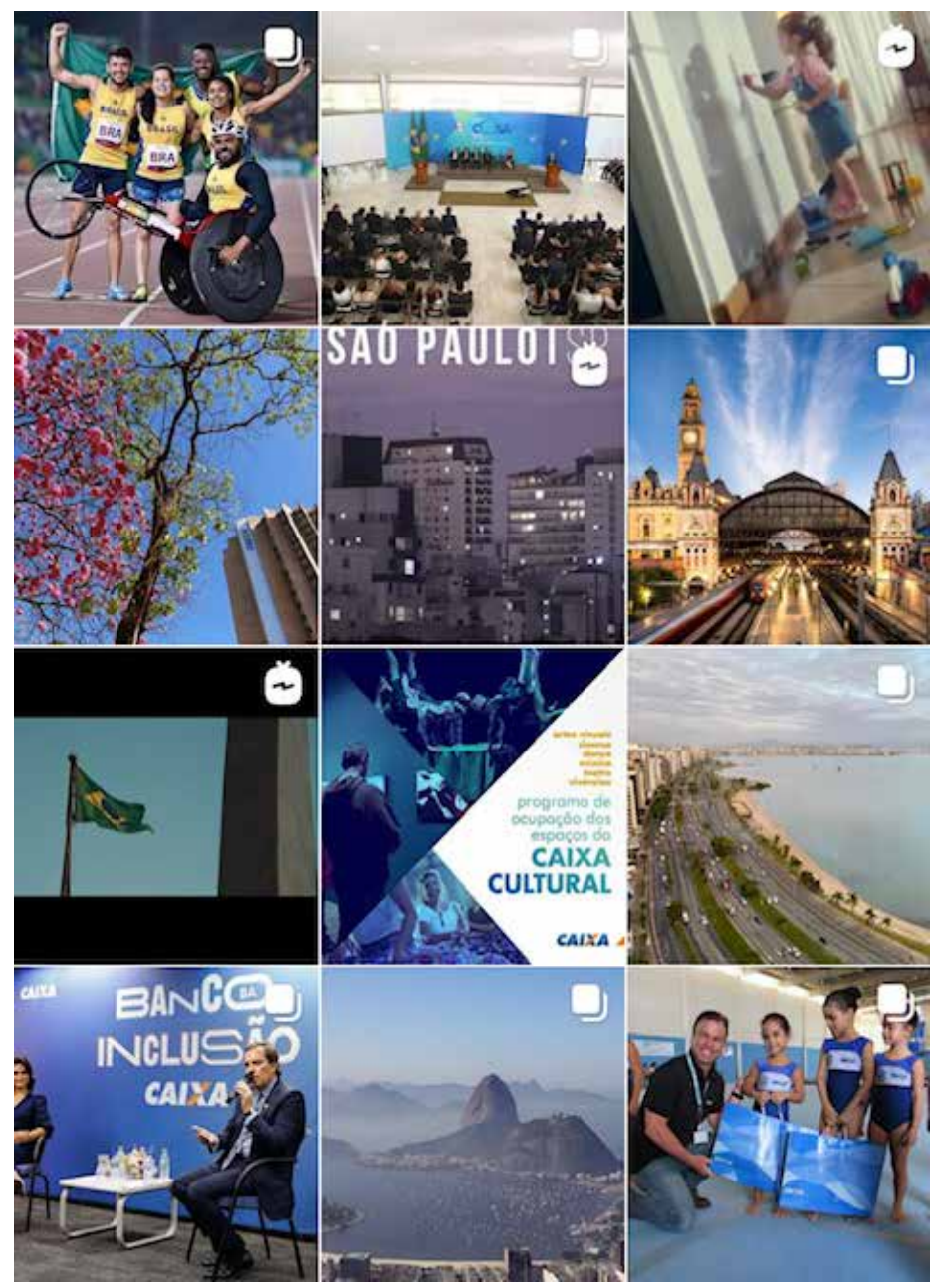

Fonte: Aplicativo Instagram. Imagem obtida em consulta ao perfil CAIXA. Acesso em 03 de setembro de 2019.

Neste trabalho, realizamos uma análise do conteúdo dessas imagens, com objetivos exploratórios. Partimos da hipótese de que as imagens compõem um processo de construção simbólica, identificatória e relacional com as organizações no ambiente digital. Não analisamos, neste momento, interações pontuais dos usuários com cada uma das imagens.

Ressalta-se que a análise de conteúdo é um conjunto de instrumentos metodológicos que se aplicam a discursos extremamente diversificados. Dessa forma, trata-se de uma hermenêutica controlada, baseada na dedução, na inferência. A análise de conteúdo, enquanto um esforço de interpretação, oscila entre dois polos, o do rigor da objetividade 
e da subjetividade do investigador (BARDIN, 1977). Portanto, atentamos que na análise em questão, há um esforço de interpretação dos autores por meio de instrumentos metodológicos, sistematizados, mas que estão sujeitos às subjetividades.

Iniciamos a análise de conteúdo da página (Fig.2) de baixo para cima, da direita para esquerda. A primeira imagem no canto direito, na parte inferior, apresenta um gestor do banco com crianças que estão recebendo kits de apoio para manutenção de um centro de treinamento de ginástica. $\mathrm{O}$ gestor aparece com crachá de identificação do banco, sorrindo, agachado, na mesma altura das crianças, de maneira mais informal e menos posada. Prevalecem os tons de azul, que são característicos da marca da empresa. A imagem sugere a proposta de aposta no futuro, com o esporte, e o investimento aos jovens. $\mathrm{Na}$ imagem do lado, no centro inferior, vemos uma imagem aérea da cidade do Rio de Janeiro. Nessa imagem é possível observar regionalização. Durante o ano de 2019, foi criado pela Caixa um programa de visitas do presidente aos municípios, com mais de 40 finais de semana, chamado programa Mais Brasil. Por meio desse programa, a instituição realizou encontros com empregados e gestores públicos em diversas cidades brasileiras. $\mathrm{Na}$ fotografia do canto inferior esquerdo há também imagem de um evento do banco com o presidente da instituição com um fundo de uma logomarca "Banco da Inclusão", ao lado de uma mulher, a primeira-dama do Presidente da República. Na imagem, sugerese preocupação do banco público com a inclusão social e com o acesso da população brasileira, ao mesmo tempo em que se reforça o papel de instituição pública, com a presença de uma representante da Presidência da República.

$\mathrm{Na}$ imagem que está na segunda linha de baixo para cima, no canto à direita, novamente, temos uma fotografia aérea de outra cidade brasileira, Florianópolis, onde percebemos a repercussão do projeto regional, Mais Brasil, de maneira a criar uma conexão simbólica com a população daquela região. Na imagem, na mesma linha, no centro, o banco apresenta o programa de ocupação dos seus espaços de cultura, a Caixa Cultural. Essa imagem também demonstra como o banco reflete suas ações culturais e demonstra que a empresa dá importância ao tema. Na outra imagem, no lado esquerdo, há um vídeo mostrando a bandeira do Brasil. Essa imagem reforça a ideia de identidade nacional, de soberania e representa a voz de um poder central, do Estado. Já na terceira linha, no canto superior à direita, vemos, na sequência duas imagens da cidade de São Paulo, novamente a repercussão do programa de regionalização, Mais Brasil, também de maneira a criar um processo identificatório com a população regional. Do lado esquerdo, uma imagem institucional do prédio da matriz do banco com enfoque em um ipê rosa, famoso na cidade de Brasília, onde se localiza a sede do banco. 
Nas últimas imagens, na parte superior, no canto direito, é possível vermos uma criança que faz parte da primeira cena de um vídeo institucional sobre acesso à casa própria, mais uma vez passando a ideia do papel social e de futuro. Na fotografia ao centro observa-se a divulgação de um evento no Palácio do Planalto com o Presidente da República. Aqui, chama atenção a imagem captada de cima para baixo, sugerindo o poder do Estado, que vê tudo do alto, por cima, em sua soberania. Também é possível ver a bandeira do Brasil presente na imagem, novamente reforçando a identidade nacional. Por fim, na última imagem, observarmos atletas brasileiros dos jogos paralímpicos, que são patrocinados pela Caixa, comemorando suas medalhas e vitórias junto com a bandeira do Brasil, em mais um reforço ao esporte, ao futuro e, ao mesmo tempo, uma demonstração da força do Estado, da identidade nacional.

As imagens do Instagram da Caixa contemplam alguns dos elementos que categorizamos para este estudo. Quando vemos as imagens postadas durante o período de 11 de julho a 01 de setembro de 2019, observamos o elemento presença. São, ao todo, 12 imagens publicadas no espaço de tempo, não representando uma grande quantidade, mas suficiente para o reforço da identidade, do self-digital do banco para o seu público de interesse. Esse elemento representa uma das principais características das mídias sociais, considerando que sem a presença, a interação no ambiente virtual não existe. Para transmitir a sensação de proximidade, legitimidade, as imagens mostram mais, aparentam uma sensação de transparência. Nesse caso, a informalidade presente nas imagens, seja na foto do gestor com as crianças recebendo o kit de ginástica, seja com o presidente falando, sem posar, em um evento com a primeira-dama, transmitem essa sensação de proximidade da gestão de um banco público com as pessoas, com os clientes, com os beneficiários, com a sociedade em geral. Apesar desses esforços para transmitir a proximidade e assim gerar empatia do público, trata-se de uma página de um perfil de uma instituição bancária. Quando falamos em bancos, eles nos remetem ao "poder" em nosso imaginário, "poder do capital financeiro". Ainda mais quando se trata de uma instituição pública, do Estado. As imagens da bandeira nacional em diversos momentos reforçam que quem está ali detém ascensão, de que existe uma hierarquia. A fotografia de cima para baixo de um evento no Palácio do Planalto também transmite essa sensação de poder de fala. Assim, podemos afirmar que as imagens que estamos analisando amenizam o caráter solene e formal, mas não o eliminam por completo.

O elemento da felicidade entra como crucial para a interação simbólica com o público. Como vimos, ele consolida o vínculo, reforça a legitimação do capital social. No caso da Caixa, o banco ainda está lidando com o "sonho da casa própria", com o 
planejamento do futuro dos jovens por meio do patrocínio e apoio ao esporte e à cultura. Vemos esse elemento presente nas imagens das crianças brincando, no sorriso do gestor com as crianças, na imagem dos atletas comemorando a vitória, o que nos remete a momentos de magia e também ao elemento da hiper-realidade, como uma imaginação idealizada que se apresenta como real.

Observa-se, ainda, que são ressaltadas as facilidades proporcionadas pelo banco durante o evento de divulgação do "Banco da Inclusão" e na divulgação dos editais de cultura. São demonstradas as características egocêntricas do banco, com suas principais vantagens, mesmo que sociais. Esse é um elemento narcísico do conteúdo produzido pelas organizações, uma estratégia associada à informação que, ao mesmo tempo em que presta o serviço sobre o produto, também mostra aos seus públicos que está diante do espelho de amor a si mesmo.

Nas imagens analisadas, temos ainda os elementos culturais que permeiam a organização e a forma com que ela demonstra sua narrativa aos seus usuários. A Caixa possui como característica ser um banco público que atende aos programas sociais e à população de baixa renda em todo o Brasil. Portanto, a inclusão e a regionalização aparecem em diversos momentos nas imagens analisadas para criar um esforço de identificação com o público diverso da instituição.

Os elementos visuais que compõem a página, de maneira geral, dão um tom de leveza, de descontração. São imagens com uma preocupação estética, com o reforço dos tons azuis e branco, e também as cores verde e amarela da bandeira nacional. Verifica-se que estão presentes características de um banco público, preocupado em demonstrar o lado social, com o futuro do país, com apoio esportivo, cultural, diverso e de inclusão popular. E, ao mesmo tempo, a organização apresenta-se como um banco formal, de mercado, ao capital financeiro, demonstrando que há relação de poder. As imagens conseguem trazer a proximidade, a presença, mas também reforçam a posição social de poder do banco, associada à figura paterna, com a presença masculina nas imagens dos dois gestores. Esses elementos apresentados reforçam as características identitárias e simbólicas da instituição e também do Estado, de maneira a nos levar ao que estamos chamando de self-digital. A partir dessa análise, sintetizamos as seguintes características identitárias refletidas no selfdigital da Caixa: futuro, regionalização, inclusão social e soberania.

Essa análise demonstra que a cultura, a identidade e a comunicação estão interligadas, conforme Ruão (2016). Elas tecem as teias de significação que a organização utiliza para operar com narrativas em uma sensação de ordem, de organização, junto a públicos internos e externos. O self-digital se apresenta com as qualidades e da maneira 
como a instituição se vê, como reconhece sua identidade, demonstrando a reflexividade, seu modelo ideal que pretende de si mesmo e também seu alter ego projetado nas mídias sociais. Essa reflexividade das qualidades e características identitárias que aparecem no digital, embora não possuam correlação absoluta, têm semelhanças entre si e constituem protótipos socialmente definidos e baseados na estrutura, na cultura e na estratégia da organização.

Assim, podemos dizer que o self-digital é construído a partir da interação entre o conteúdo das imagens organizacionais e os públicos da organização. Parece haver um aspecto recursivo nessa interação. Quanto mais se mostram para os seus públicos, as organizações parecem ter maior necessidade de "serem vistas", de se legitimarem. Entretanto, as relações organizacionais estão longe de acontecerem em ambientes de fluxos relacionais ordenados, racionais. Elas podem ser tensionadas e levadas à desordem a qualquer tempo. Dessa maneira, quanto mais imagens são postadas, mais a relação de identificação acontece, por meio das características identitárias da instituição refletidas no self-digital.

\section{Considerações finais}

Com o objetivo de compreender como as organizações constroem e representam suas identidades nos ambientes digitais pelas imagens, observamos neste artigo que as relações de interação ocorrem a partir da construção de narrativas permanentes, produzidas/ reproduzidas com essas imagens pelas organizações nas mídias sociais por meio do self-digital, com uma sensação de ordem, coerência, que permite o reconhecimento e a legitimação pelo outro. Avaliamos que a reflexividade do self no ambiente digital pelas imagens possui algumas características para gerar o elo de aproximação com usuários:

Tem caráter fluido, permeado pela sensação de visibilidade ao outro (presença);

Possui confronto permanente com seu princípio egocêntrico para se adaptar à realidade (narcisismo);

Possui necessidade de atributo que lhe ofereça autoconfiança, legitimidade a partir de um modelo sociológico (felicidade);

Atua na imaginação dos indivíduos, em esforço que leva à reverência, idolatria (hiper-realidade);

Possui forte ligação com a cultura da organização, tornando a tríade culturaidentidade-comunicação, citadas por Ruão (2016). 
No caso de estudo da Caixa, observamos que a instituição possui presença no Instagram durante o período analisado, tenta gerar empatia e legitimidade com a sensação de transparência de suas ações. Utiliza elementos que demonstram e projetam felicidade, magia e hiper-realidade com crianças, com a sugestão de apoio no futuro. O elemento cultural também está fortemente presente, demonstrando uma referência clara à missão do banco de ser voltado ao desenvolvimento social da população brasileira, com acesso e inclusão e também de regionalização. Ao mesmo tempo, a instituição ainda impõe sua formalidade por meio da utilização solene da bandeira nacional, do poder do Estado. Os tons das cores e elementos da marca também estão presentes nas imagens analisadas, mas podem ser ressaltados a fim de criar sempre a identificação imediata do público com as ações e imagens divulgadas. $\mathrm{O}$ banco não apresenta elementos identitários que o aproximem de processos de inovações tecnológicas, ou até mesmo que gerem maior informalidade.

Reforçamos que o self-digital da Caixa pode/deve ser permanentemente atualizável por meio das postagens e da recursividade do processo identificatório, uma vez que ele reflete o que o banco é (alter ego, sombra de si mesmo) e o que o banco quer ser (modelo ideal), o que resulta na formação de uma imagem para seu público. A atualização do self-digital acontece a partir da tríade cultura, identidade e comunicação. A Comunicação Organizacional é referida neste estudo como um fio condutor de alinhamento dos discursos, de significações, que são tensionados pelos sujeitos da organização, de maneira a refletir a identidade. Entretanto, vimos que a forma assumida pela identidade das organizações é simbólica, provisória e é permanentemente atualizada. A construção da identidade das organizações nas mídias sociais se formula e reformula incessantemente, em uma constante "autoafirmação de si", com o objetivo de manter a sensação de ordem das narrativas do seu duplo. Essa reformulação necessita de instantaneidade, para não se tornar uma narrativa atrasada sobre a instituição. Também não possui território definido. Nesse contexto, as imagens (re)produzem narrativas e elementos da cultura da organização que influenciam as normas, costumes, ideologia, crenças e também o próprio ambiente digital do qual ela faz parte.

\section{Referências}

BAITELLO JUNIOR, Norval. A era da iconofagia: reflexões sobre a imagem, comunicação, mídia e cultura. São Paulo: Paulus, 2014. 
BARDIN, Laurence. Análise de Conteúdo. Lisboa: Edições 70, 1977.

BALDISSERA, Rudimar. Tensões dialógico-recursivas entre a comunicação e a identidade organizacional. Organicom, São Paulo, n.7, p. 230-243, 2007. Disponível em: https://www.revistas.usp.br/organicom/article/view/138954. Acesso em: 26 abr. 2020 .

BALDISSERA, Rudimar. A teoria da complexidade e novas perspectivas para os estudos de comunicação organizacional. In: KUNSCH, Margarida (Org.). Comunicação Organizacional. Volume 1. São Paulo: Saraiva, 2009.

CARRERA, Fernanda. O imperativo da felicidade em sites de redes sociais: Materialidade como subsídio para o gerenciamento de impressões sempre positivas. Revista Eptic Online. v.16, n.1, p.33-44, jan-abr, 2014.

ETKIN, Jorge; SCHVARSTEIN, Leonardo. Identidad de las organizaciones: invariancia y cambio. Buenos Aires: Paidós, 2011.

FLUSSER, Vilém. Filosofia da Caixa Preta. São Paulo: Annablume, 2011.

FREIRE FILHO, João. Ser feliz hoje: Reflexões sobre o imperativo da felicidade. Rio de Janeiro: Editora FGV, 2010.

HAN, Byung-Chul Han. No Enxame: Reflexões sobre o digital. Lisboa: Relógio D'agua Editores, 2016.

MCLUHAN, Marshall. Os meios de comunicação como extensões do homem. São Paulo: Editora Pensamento Cultrix, 1964, edição 2007.

MORIN, Edgar. Ciência com consciência. Rio de Janeiro: Bertrand Brasil, 2000.

MORIN, Edgar. O Método: A vida da vida. Portugal: Publicações Europa-America, 1980.

MORIN, Edgar. O Método 3: O conhecimento do conhecimento. Porto Alegre: Sulina, 2012 .

RECUERO, Raquel. O que é mídia social? Disponível em: http://www.raquelrecuero. com/arquivos/o_que_e midia_social.html. Acesso em: 22 ago. 2019.

RECUERO, Raquel. Mídia social $x$ Rede social. Disponível em: http://www. raquelrecuero.com/arquivos/midia_x_rede_social.html. Acesso em: 22 ago. 2019. 
RUÃO, Teresa. A organização comunicativa. Teoria e prática em comunicação organizacional. Centro de estudos de comunicação e sociedade. Universidade do Minho, Braga. Portugal, 2016.

OLIVEIRA, Tatiane. Self-digital como uma perspectiva sobre a construção das identidades organizacionais nas mídias sociais. Dissertação de mestrado apresentada ao programa de pós-graduação strictu-sensu em Comunicação da Universidade Católica de Brasília. Brasília, 2019.

\section{CONSULTAS ON-LINE}

CANALTECH. Instagram bate marca de 1 bilhão de usuários ativos. Disponível em: https://canaltech.com.br/redes-sociais/instagram-bate-marca-de-1-bilhao-de-usuariosativos-116344/. Acesso em: 22 ago, 2019.

CAIXA. Sobre a Caixa: Caixa compromisso com o Brasil. Disponível em: http:// www.caixa.gov.br/sobre-a-caixa/apresentacao/Paginas/default.aspx. Acesso em: 26 ago. 2019.

GLOBAL DIGITAL REPORT. Disponível em: https://wearesocial.com/global-digitalreport-2019. Acesso em: 18 dez. 2019 (pp.84-114).

INSTAGRAM. Empresas. Disponível em: https://business.instagram.com/gettingstarted/\#why-instagram. Acesso em: 18 dez. 2019.

\footnotetext{
${ }^{i}$ Doutoranda em Comunicação; Mestre em Comunicação pela UCB. Chefiou a Assessoria de Impren-sa do banco público Caixa Econômica Federal. E-mail: tatiane.rco@gmail.com

${ }^{i i}$ Professor e pesquisador do Programa de Pós-Graduação em Educação e do Mestrado Profissional Inovação em Comunicação e Economia Criativa da Universidade Católica de Brasília. E-mail: vic-torlaus@gmail.com
} 